\title{
OXYTOCIN IN INDUCTION OF LABOR IN PREGNANCY WITH GROUP B STREPTOCOCCAL PORTAGE
}

\author{
MIHAELA CORINA RADU ${ }^{1}$, ANCA IRINA DUMITRESCU ${ }^{2}$, ADRIAN CALIN BOERU ${ }^{3}$, \\ LOREDANA SABINA CORNELIA MANOLESCU ${ }^{4}$, OANA ROXANA DUMITRESCU ${ }^{5}$, \\ PETRU ARMEAN
}

${ }^{1,3,5}$ Hospital of Obstetrics and Gynaecology, Ploieşti, 1,2,4,6 "Carol Davila” University of Medicine and Pharmacy, Bucharest

\begin{abstract}
Keywords: oxytocin, induction of labor, group $B$ Streptococcus - GBS, GBS infection

Abstract: In the last two decades, group B streptococcus (GBS) infection has established itself as a major cause of perinatal morbidity and mortality. The purpose of this study is to identify if the electively induced labor with oxytocin in women with positive cultures of Streptococcus agalactiae, namely the group B streptococcus (GBS), helps the mother and fetus and decreases the risk associated with perinatal transmission of GBS compared with the spontaneous labor. Results associated with induction of labor with oxytocin compared with spontaneous labor in pregnant women who have GBS - positive cervical cultures, are also used to determine whether induction of labor decreases the risk of complications from GBS infection.
\end{abstract}

\section{INTRODUCTION}

Streptococcus agalactiae or group B streptococcus (GBS) can colonize the vagina and cervix in the absence of symptoms. It is part of the normal flora of the female genital tract and can be a major cause of sepsis and neonatal meningitis. It is not a cause of sexually transmitted infection. $(1,2,3)$ GBS belongs to group I, the pyogenic group of streptococci.(2) The pregnant woman, vaginally colonized with GBS may develop: febrile endometritis with blood dissemination or secondary endocardial or meningeal localization. In the newborn, GBS produces two distinct forms of invasive disease: The disease begins early in the first week of life, and the newborn develops one or more of the following: sepsis, pneumonia, meningitis, osteomyelitis and septic arthritis can be acquired in the womb or at birth.(1,4) The second form is the late-onset disease and occurs after the first week of life, but can occur up to a few months of age. It is transmitted through human contact, and the newborn develops: meningitis or sepsis. Mortality is about $50 \%$. Survivors may have: speech disorders, hearing impairments, visual impairments, psychomotor retardation, convulsions.(1) Vertical mother-to-child transmission of GBS is $40 \%-73 \%$ in pregnant women with positive cultures, but only $1 \%-2 \%$ of newborns develop early infection.(5)

The diagnosis in pregnant women is made by Gram staining of vaginal secretion and bacterial culture from secretions taken from the vagina / cervix and rectum in the 3537 week of gestation.(2,3) In the newborn, the diagnosis depends on the symptoms and the type of damage. The GBS portage in the vagina is intermitent, which means that an analysis at the beginning of pregnancy can be positive for bacteria, and after a while the result will be negative, and then positive again, without any treatment. $(6,7)$ The large intestine is the source of this recolonization. The identification of GBS in the urine in the case of a positive urine culture always requires treatment, even in the absence of symptoms of urinary tract infection. The treatment will depend on the antibiogram. In the absence of treatment, the presence of bacteria in the urine can cause premature birth, pyelonephritis. $(6,7)$

It is estimated that globally about $10-30 \%$ of pregnant women carry GBS in the genital tract (1). It was observed that in pregnant women with GBS bacteriuria there is a higher risk of: premature birth $(15.3 \%$ vs $7.9 \%)$, premature rupture of membranes (10.7 vs 7.9), growth restriction syndrome intrauterine, abortion.(8)

$G B S$ can be transmitted antepartum, intrapartum and postpartum. The most vulnerable are premature newborns or those with gestational age $<37$ weeks, newborns by natural birth with ruptured membranes more than 18 hours before birth or any newborn by natural birth if the mother is carrying streptococcus group B.

The risk of congenital infection varies according to studies up to $15 \%$ and is correlated with the presence of group B streptococcus in the urine. $(1,3,9)$

Prophylaxis of maternal-fetal transmission is done by screening vaginal secretion and rectal impression for GBS in all pregnant women, in week 35-37 of gestation and chemoprophylaxis with ampicillin or penicillin administered intravenously to pregnant women with GBS, at the beginning and during labor, at birth naturally or by cesarean section.(10) In pregnant women allergic to penicillin, then, erythromycin, clindamycin, cefazoline are recommended. $(1,3,10)$ There is no vaccine yet.

In current obstetric practice there are multiple methods of induction of labor, some less used, others routinely used. The most common birth induction technique is the pharmacological method: oxytocin infusion. Oxytocin is a peptide hormone synthesized by the paraventricular and supraoptic nuclei of the hypothalamus and stored in the neurohypophysis. Oxytocin, the

${ }^{1}$ Corresponding author: Loredana Sabina Cornelia Manolescu, Aleea Poiana Sibiului, Nr. 1, Bl. C4, Sc. 2, Ap. 41, Sector 6, Bucureşti, România, Email: loredana.manolescu@umfcd.ro, Phone: +40723 699253

Article received on 27.07.2020 and accepted for publication on 24.08.2020 


\section{CLINICAL ASPECTS}

hormone that triggers contractions of the uterus is used to induce labor. It may also indirectly determine filling the milk ducts of the breast for breastfeeding. In order to start labor contractions quickly, in about half an hour, or intensify them, a synthetic oxytocin can be administered to pregnant women. Its administration has a significant effect when the amniotic membranes are broken.(11) Alfirevic (12) showed in 2016 that induction by artificial rupture of amniotic membranes with oxytocin administration is one of the methods with the highest probability of birth in 24 hours.

As part of the health care insurance program all childbearing women in Romania have the right to antenatal care.(13) During at the antenatal care all women are routinely screening for GBS

The aim of this study is to identify whether electively oxytocin-induced labor in women with GBS-positive cervical cultures helps the mother and fetus and decreases the risk associated with perinatal transmission of GBS compared to spontaneous labor.

\section{MATERIALS AND METHODS}

This study compares the labor, delivery, and fetal outcome of 50 parturients in which labor was electively induced with oxytocin with 50 matched controls that began labor spontaneously. All patients gave birth at Obstetrics and Gynaecologic Hospital in Ploiesti, Romania and the criteria for admission was the GBS colonization of the cervix in the 35-37 week of gestation and the rupture of membranes at the moment of birth. The patients were between 37 and 41 weeks of gestation and had no medical or obstetric conditions necessitating induction. All pregnant women included in the study, presented in week 35-37 the positive cervical culture for group B Streptococcus. Prophylaxis of maternal-fetal transmission was done with ampicillin administered intravenously to pregnant women with GBS, at the beginning and during labor at birth. No pregnant woman was allergic to ampicillin. The cases and controls were matched for age group, parity, gestational age, and delivering obstetrician. The procedure was fully discussed with the mother, explaining the technique to be used and any possible side-effects and consequences of failure (cesarean section). The childbearing woman gave her informed written consent. The pregnant women included in the study were divided into two groups:

Lot $\mathrm{A}$ - includes 50 pregnant women in whom, in order to reduce the risk of infectious complications (by shortening the duration of labor) due to GBS, oxytocin was administrated to induce labor. It was used oxytocin $5 \mathrm{IU} / \mathrm{ml}$ concentrate for solution for infusion in $500 \mathrm{ml}$ saline $9 \%$ (intravenous infusion).

Lot B - CONTROL LOT, includes 50 pregnant women in whom labor occurred spontaneously, without administration of oxytocin, although pregnant women had a history of cervix infection with GBS.

Each pregnant woman was evaluated according to the pregnancy investigation program regulated by the clinical guidelines. $(14,15)$

In the case of both groups, at admission, the Bishop score was determined, the fetal status was determined by cardiotocography and fetus and ultrasonographic placentometry and tests were collected to screen for GBS infection.

To assess the degree of maturation of the cervix, the Bishop scale was applied. The following indicators were evaluated: consistency, length of the cervix, permeability of the cervical canal, position of the cervix in relation to the pelvic axis, the level of the fetus in relation to the sciatic spine. Each indicator was rated from 0 to 3 points. The total score (in points) expresses the degree of maturation of the cervix. At the assessment with 0-5 points, the cervix was considered "immature"; of 6-7 points - insufficiently "matured"; greater than 8 - "mature". Prepared biological cervix is the main condition for the natural onset of labor through natural birth routes.(16)

In order to determine the effect of drug induction of birth on the condition of the uteroplacental and fetoplacental complex, the condition of the fetus was evaluated by performing cardiotocography and dopplerometry. Cardiotocography (CTG) is a non-invasive method of assessing fetal status and maternal uterine tone.

The interpretation of the CTG results was based on four parameters: baseline rhythm, variability, accelerations, decelerations.(16) (table no. 1). A CTG route is classified as normal when all 4 criteria fall into the category of normal or safe. The CTG route is considered suspicious if one criterion is suspicious, the others being normal. This type of CTG requires continuous recording, with the evaluation of the route every 30 minutes. The CTG pathway is classified as pathological when there is at least one pathological criterion or at least 2 suspicious criteria. This type of CTG justifies the continuous recording, with the evaluation of the route every 10 minutes and imposes certain actions (modification of the maternal position, administration of intravenous solutions, tocolysis etc.).

Table no. 1. Fetal monitoring during labor

\begin{tabular}{|l|l|l|l|}
\hline Parameters & Normal & Suspect & Pathological \\
\hline Basal rhythm & $110-160$ & $\begin{array}{l}<10 \\
>160\end{array}$ & $<100$ \\
$>180$ \\
\hline $\begin{array}{l}\text { Oscillations } \\
\text { amplitude, } \\
\text { bpm }\end{array}$ & $5-25$ & $\begin{array}{l}<5(<40 \mathrm{~min}) \\
>25(>10 \mathrm{~min})\end{array}$ & $\begin{array}{l}<5(90 \mathrm{~min}) \\
\text { sinusoidal CTG } \\
\geq 10 \text { min }\end{array}$ \\
\hline Accelerations & $\geq 2 / 20 \mathrm{~min}$ & $\begin{array}{l}\text { absent (40 } \\
\text { min) }\end{array}$ & \multicolumn{1}{|c|}{} \\
\hline Decelerations & absent & $\begin{array}{l}\text { sporadic (of } \\
\text { any kind, } \\
\text { except for } \\
\text { severe ones) } \\
\text { unique } \\
\text { extensions }<3 \\
\text { minutes }\end{array}$ & $\begin{array}{l}\text { - periodic, } \\
\text { sporadic or ate for a } \\
\text { severe variables } \\
\text { period of 30 min } \\
\text { mintended }>3 \\
\text { minutes }\end{array}$ \\
\hline
\end{tabular}

Feto- and placentometry ultrasound were performed using the Samsung Premium RS85A ultrasound device, using a transabdominal probe with a frequency of $1.8 \mathrm{MHz}$, and included the following parameters: biparietal diameter; the circumference of the head and abdomen of the fetus; length of the femur. The results obtained were correlated with the normograms of the Hadloc 84 percentile curves.(17) Also, the probable mass of the fetus was calculated by the calculation method of Hadlock et al. (18), using percentile curves.(19,20)

During the ultrasonographic examination, the location, morphology, degree of maturation, placental thickness, umbilical cord pathology, amniotic fluid volume, fetal development abnormalities were assessed.

Fetal Dopplerometry was used to assess the functional status of the fetoplacental system. The following were analyzed: umbilical, uterine and middle cerebral artery circulation of the fetus.

Chorioamnionitis is an important risk factor for earlyonset GBS disease in women with GBS colonization and can reflect an intrauterine onset of infection in the neonate.

All pregnant women included in the study, as well as newborns received antibioprophylaxis according to the recommendations of clinical guidelines.(21)

There are international differences in testing the presence of GBS in pregnant women. In England, the Royal College of Obstetricians and Gynecologists (RCOG) does not recommend testing pregnant women for GBS, but in the United 


\section{CLINICAL ASPECTS}

States, the American Congress of Obstetricians and Gynecologists (ACOG) recommends that every woman should be tested by analyzing vaginal discharge between 35 and 37 weeks of pregnancy. One reason for this difference is that the United States faces a much higher neonatal mortality due to neonatal GBS infection. Even if GBS is detected at 35-37 weeks, antibiotic treatment is given only at birth and in Americans. After birth, all newborns were evaluated by the Apgar score at $1 \mathrm{~min}$ and $5 \mathrm{~min}$ after birth by the obstetrician and the neonatologist. For statistical analysis we used Microsoft Office package - Word and Excel. We calculated the $p$ - value with the e chi-square statistic test; we considered significant result when $p<.05$.

\section{RESULTS AND DISCUSSIONS}

The age of the women included in the study is shown in table no. 2. The data obtained show that patients in lot A are older, the average age being 28.16 years, compared to patients in lot $\mathrm{B}$, whose average age is 25.48 years.

Following the distribution of patients according to the environment of origin, it was highlighted that in both lots are predominantly pregnant women from rural areas. Essential differences between these two groups were not highlighted. Therefore, $64 \%(\mathrm{~N}=34)$ of the patients in the basic lot and $72 \%$ $(\mathrm{N}=36)$ of the patients in the control lot are from rural areas, $p$ $=.868717$

In most cases, namely $84 \%(\mathrm{~N}=42)$, for patients who received oxytocin during labor, and $78 \%(\mathrm{~N}=39$, ) for those in the reference lot, there was no registered marriage.

The analysis of the level of studies showed that in both study lots, patients with secondary education predominated, without essential differences between lots, $p=.520606$ namely $58 \%(\mathrm{~N}=29)$ of patients in lot $\mathrm{A}$ and $50 \%(\mathrm{~N}=25)$ of the patients in the control lot had secondary education. Higher education had $12 \%(\mathrm{~N}=6)$ of patients in lot $\mathrm{A}$ and $6 \%(\mathrm{~N}=3)$ of patients in the control lot. Elementary studies had $24 \%(\mathrm{~N}=$
12) of patients in $\mathrm{A}$ and $32 \%(\mathrm{~N}=16)$ of patients in the control lot. The rest of the patients had no studies, $8 \%(\mathrm{~N}=4)$ from lot A and $12 \%(\mathrm{~N}=6)$ from the control lot.

Patient' $\mathrm{s}$ education is very important if the goal is a successful labor induction. Beside the medical need for the procedure the pregnant woman's expectations have to be managed and fulfilled. This is why in the preparation of the labor, the pregnant woman must know the potential risks of an induced labor and decide together with the medical team the reasons for labor induction and the timing as well, if medical condition allows it.

It is known that adipose tissue is hormonally active (22), therefore an excessive weight gain, in normal weight women, may determine an altered metabolic status and endocrine environment unfavorable to spontaneous initiation of labor. Our study showed an increased share of pregnant women with body mass index (BMI) between 26-35 in lot A (table no $3)$.

The distribution of pregnant women examined by parity and gestation showed (table no. 4) that in the control group predominated patients with multiple gestation pregnancy and primiparous, and in case of birth induced by oxytocin infusion, primigest and primiparous. Thus, in the baseline lot $48 \%(\mathrm{~N}=24)$ of patients were primed, compared to the control lot where this indicator was $34 \%(\mathrm{~N}=17)$. Primiparous predominated both in the baseline lot $(56 \%, \mathrm{~N}=28)$ and in the control lot $(48 \%, \mathrm{~N}=24)$. Women with multiple gestation pregnancy were higher in the control lot $(8 \%, \mathrm{~N}=4)$ compared to the baseline lot $(4 \%, \mathrm{~N}=2)$.

High parity and overweight of the pregnant mother are recognized predictive factors for the high weight of the newborn at birth. $(23,24)$ However, only a few studies are addressed to the mechanism behind this association. Excessive fetal growth in ectopic life increases maternal risk for obstetric complications, even influencing maternal mortality. $(25,26)$

Table no. 2. Distribution of pregnant women by age groups

\begin{tabular}{|l|l|l|l|l|l|l|}
\hline Age (years) & $\begin{array}{l}\text { 15-19 years } \\
\text { N (\%) }\end{array}$ & $\begin{array}{l}\mathbf{2 0 - 2 4} \text { years } \\
\mathbf{N}(\mathbf{\%})\end{array}$ & $\begin{array}{l}\mathbf{2 5 - 2 9} \text { years } \\
\mathbf{N}(\%)\end{array}$ & $\begin{array}{l}\mathbf{3 0 - 3 4} \text { years } \\
\mathbf{N}(\mathbf{\%})\end{array}$ & $\begin{array}{l}\mathbf{3 5 - 3 9} \text { years } \\
\mathbf{N}(\%)\end{array}$ & $\begin{array}{l}\mathbf{4 0 - 4 4} \text { years } \\
\mathbf{N}(\%)\end{array}$ \\
\hline LOT A & $5(10 \%)$ & $10(20 \%)$ & $16(32 \%)$ & $9(18 \%)$ & $8(16 \%)$ & $2(4 \%)$ \\
\hline LOT B & $7(14 \%)$ & $19(38 \%)$ & $11(22 \%)$ & $8(16 \%)$ & $5(10 \%)$ & 0 \\
\hline
\end{tabular}

Table no. 3. Distribution of pregnant women by BMI and height

\begin{tabular}{|l|l|l|l|l|l|l|}
\hline \multirow{2}{*}{ Anthropometric data } & \multicolumn{3}{|c|}{ BMI } & \multicolumn{2}{c|}{ Height } \\
\cline { 2 - 7 } & Under 25 & $\mathbf{2 5 - 3 0}$ & $\mathbf{3 1 - 3 5}$ & Over 36 & Under 150 cm & Over 150 cm \\
\hline Lot A & $9(18 \%)$ & $18(36 \%)$ & $19(38 \%)$ & $3(6 \%)$ & $6(12 \%)$ & $44(88 \%)$ \\
\hline Lot B & $18(36 \%)$ & $14(28 \%)$ & $13(26 \%)$ & $1(2 \%)$ & $5(10 \%)$ & $45(90 \%)$ \\
\hline
\end{tabular}

Table no. 4. Distribution of pregnant women examined by gestation and parity

\begin{tabular}{|l|l|l|l|l|l|l|l|l|l|l|}
\hline Gestation Parity & I G & I P & I G & II P & III G & III P & IV G & IV P & V G and over & V and over \\
\hline LOT A & $24(48 \%)$ & $28(56 \%)$ & $8(16 \%)$ & $8(16 \%)$ & $7(14 \%)$ & $7(14 \%)$ & $5(10 \%)$ & $5(10 \%)$ & $10(20 \%)$ & $2(4 \%)$ \\
\hline LOT B & $16(32 \%)$ & $24(48 \%)$ & $18(36 \%)$ & $6(12 \%)$ & $6(12 \%)$ & $6(12 \%)$ & $4(8 \%)$ & $10(20 \%)$ & $26(52 \%)$ & $4(8 \%)$ \\
\hline
\end{tabular}

Table no. 5. Frequency of others pathology of patients included in study $\mathbf{N}(\%)$.

Table no. 5. Frequency of others pathology of patients included in study N (\%).
\begin{tabular}{|l|l|l|l|l|}
\hline Diseases & Diseases of the cardiovascular system & Diseases of the urinary system & Endocrine diseases & Obesity \\
\hline LOT A & $18(36 \%)$ & $9(18 \%)$ & $6(12 \%)$ & $4(8 \%)$ \\
\hline LOT B & $5(10 \%)$ & $8(16 \%)$ & $2(4 \%)$ & $7(14 \%)$ \\
\hline
\end{tabular}

Table no. 6. Complications of current birth in parturients included in the study

\begin{tabular}{|c|c|c|c|c|c|c|}
\hline \multirow{4}{*}{$\begin{array}{l}\text { Complications } \\
\text { LOT A }\end{array}$} & DPPNI & Fetal suffering & Postpartum haemorrhage & & rupture & Episiotomy \\
\hline & \multirow[t]{3}{*}{$6(12 \%)$} & \multirow[t]{3}{*}{$12(24 \%)$} & \multirow[t]{3}{*}{$27(54 \%)$} & Vagina & $14(28 \%)$ & \multirow[t]{3}{*}{$38(76 \%)$} \\
\hline & & & & Cervix & $16(32 \%)$ & \\
\hline & & & & Hematoma & $8(16 \%)$ & \\
\hline \multirow[t]{3}{*}{ LOT B } & \multirow[t]{3}{*}{$4(8 \%)$} & \multirow[t]{3}{*}{$10(20 \%)$} & \multirow[t]{3}{*}{$25(50 \%)$} & Vagina & $4(8 \%)$ & \multirow[t]{3}{*}{$22(44 \%)$} \\
\hline & & & & Cervix & $8(16 \%)$ & \\
\hline & & & & Hematoma & $2(4 \%)$ & \\
\hline
\end{tabular}


CLINICAL ASPECTS

Table no. 7. Distribution of newborns by Apgar score at 1 minute

\begin{tabular}{|l|l|l|l|l|l|l|}
\hline APGAR SCORE & $\mathbf{1 0}$ & $\mathbf{9}$ & $\mathbf{8}$ & $\mathbf{7}$ & $\mathbf{6}$ & 5 AND UNDER 5 \\
\hline LOT A & $11(22 \%)$ & $17(34 \%)$ & $12(24 \%)$ & $4(8 \%)$ & $3(6 \%)$ & $3(6 \%)$ \\
\hline LOT B & $10(20 \%)$ & $20(40 \%)$ & $14(28 \%)$ & $2(4 \%)$ & $4(8 \%)$ & 0 \\
\hline
\end{tabular}

Table no. 8. Distribution of newborns by anthropometric data

\begin{tabular}{|c|c|c|c|c|c|c|c|c|c|}
\hline \multirow[b]{2}{*}{ Anthropometric data } & \multicolumn{6}{|c|}{ weight } & \multicolumn{3}{|c|}{ waist } \\
\hline & $\begin{array}{l}2000- \\
2490 \mathrm{~g}\end{array}$ & $\begin{array}{l}2500- \\
2990 \mathrm{~g}\end{array}$ & $\begin{array}{l}3000- \\
3490 \mathrm{~g}\end{array}$ & $\begin{array}{l}3500- \\
3990 \mathrm{~g}\end{array}$ & $\begin{array}{l}4000- \\
4490 \mathrm{~g}\end{array}$ & $\begin{array}{l}\text { Above } \\
4500\end{array}$ & $\begin{array}{l}45-49 \\
\mathrm{~cm}\end{array}$ & $50-54 \mathrm{~cm}$ & $\begin{array}{l}\text { Above } 55 \\
\mathrm{~cm}\end{array}$ \\
\hline $\begin{array}{l}\text { Lot A } \\
\mathrm{N} / \%\end{array}$ & $\begin{array}{l}2 \\
(4 \%)\end{array}$ & $\begin{array}{l}10 \\
(20 \%)\end{array}$ & $\begin{array}{l}15 \\
(30 \%)\end{array}$ & $\begin{array}{l}13 \\
(26 \%)\end{array}$ & $\begin{array}{l}6 \\
(12 \%)\end{array}$ & $\begin{array}{l}4 \\
(8 \%)\end{array}$ & $\begin{array}{l}6 \\
(12 \%)\end{array}$ & $\begin{array}{l}36 \\
(72 \%)\end{array}$ & $\begin{array}{l}8 \\
(16 \%)\end{array}$ \\
\hline $\begin{array}{l}\text { Lot B } \\
\mathrm{N} / \%\end{array}$ & $\begin{array}{l}1 \\
(2 \%)\end{array}$ & $\begin{array}{l}12 \\
(24 \%) \\
\end{array}$ & $\begin{array}{l}16 \\
(32 \%)\end{array}$ & $\begin{array}{l}14 \\
(28 \%) \\
\end{array}$ & $\begin{array}{l}5 \\
(10 \%) \\
\end{array}$ & $\begin{array}{l}2 \\
(4 \%)\end{array}$ & $\begin{array}{l}8 \\
(16 \%)\end{array}$ & $\begin{array}{l}38 \\
(76 \%)\end{array}$ & $\begin{array}{l}4 \\
(8 \%)\end{array}$ \\
\hline
\end{tabular}

Table no. 9. Distribution of puerperal complications

\begin{tabular}{|l|l|l|l|l|l|l|l|}
\hline Complications & Endometritis & Hyperthermia & $\begin{array}{l}\text { Uterine } \\
\text { hemorrhage / } \\
\text { Uterine } \\
\text { relaxation }\end{array}$ & $\begin{array}{l}\text { Placental } \\
\text { residues }\end{array}$ & Lohiometry & $\begin{array}{l}\text { Complications } \\
\text { of } \\
\text { postoperative } \\
\text { wound }\end{array}$ & $\begin{array}{l}\text { Exacerbation of } \\
\text { extragenital } \\
\text { pathology }\end{array}$ \\
\hline Lot A & $4(8 \%)$ & $6(12 \%)$ & $12(24 \%)$ & $4(8 \%)$ & $6(12 \%)$ & $4(8 \%)$ & $5(10 \%)$ \\
\hline Lot B & $5(10 \%)$ & $4(8 \%)$ & $15(30 \%)$ & $8(16 \%)$ & $6(12 \%)$ & $1(2 \%)$ & $6(12 \%)$ \\
\hline
\end{tabular}

The analysis of the structure of the underlying others disease, shows that in pregnant women with oxytocin infusioninduced birth, a worsened somatic history was present in $74 \%$ $(\mathrm{N}=37)$ of cases, compared to the control group where others pathology was detected only in $44 \%(\mathrm{~N}=22)$ of cases. In the structure of others pathology in both lots predominates the pathology of the cardiovascular system and urinary system. Pregnancy-induced hypertension was recorded in patients born with oxytocin infusion-induced birth in $36 \%(\mathrm{~N}=18)$ cases, compared with $10 \%$ of cases $(\mathrm{N}=5)$ in the control lot, with a statistically significant difference $(p=.002008)$. Urinary tract diseases (mainly urinary tract infections) more frequently, 18\% $(\mathrm{N}=9)$ were detected in pregnant women with birth induced by oxytocin perfusion, while among patients in the control group this indicator was $16 \%(\mathrm{~N}=8)$. Diseases of the endocrine system (mainly diabetes and gestational diabetes) were diagnosed more frequently in group A and they constituted $12 \%$ $(\mathrm{N}=6)$ compared to $4 \%(\mathrm{~N}=2)$ in the control group (table no. $5)$.

In most patients in the basic lot $(84 \%, \mathrm{~N}=42)$ the birth took place vaginally, and cesarean section was performed only in $16 \%(\mathrm{~N}=8)$ of cases. A different situation was mentioned in the control lot, the cesarean section being performed more frequently, compared to the basic lot, and constituted on average $52 \%(\mathrm{~N}=26)$; vaginal birth was performed in only $48 \%(\mathrm{~N}=24)$ of the pregnant women ( $p=$ .000145 statistically).

The fact that the vast majority of pregnant women included in the induction study, gave birth vaginally, without intervention, demonstrates the effectiveness of induction when cases are well managed.

In the statistical analysis of pregnant women who had an unfavorable Bishop score at the beginning of labor, no correlation was found between it and the mode of birth, confirming that the local unfavorable situation at the beginning of labor should not be an indication per cesarean section, in the absence of other contraindications. The unfavorable cervix situation at the beginning of labor is not an indication for cesarean section. $(27,28)$ Structural changes in the cervix are a complex chain of histochemical changes in the structure of collagen, such as: destabilization, a general change in the connective tissue of the cervix (hydration, weakening of the collagen network with a reduction in the amount of collagen); reorganization of the structure and concentration of proteoglycans; acquiring new physical, mechanical properties (softness, elasticity, suppleness) of the cervical tissue.(29) Thus, at admission, $76 \%(\mathrm{~N}=38)$ of the parturients in the study lot had a Bishop score of 6 or above 6 , and only $24 \%(\mathrm{~N}=12)$ of the patients in the control lot had an unfavorable Bishop score. The mean value of the Bishop score in research lot $\mathrm{A}$ was assessed with 6.88 points, and in control lot B higher 6.68 points, with the difference statistically confirmed. The $p$-value is $<.00001$. The result is significant at $\mathrm{p}<.05$.

Evaluating the onset of births, we can mention that premature rupture of amniotic membranes revealed a significant amniotic fluid for the presence of meconium which complicated the birth more frequently among patients in lot A. Thus, if the presence of meconium in amniotic fluid, in lot $\mathrm{A}$, occurred in $76 \%(\mathrm{~N}=38)$ of cases and in $28 \%(\mathrm{~N}=14)$ of cases in the control lot $(p<.00001)$. The result is significant at $p<.05$. Although the difference is significant, emergency cesarean section for fetal distress did not predominate in the lot A.

Abnormalities of birth activity were diagnosed as follows: in the baseline lot (lot A), DPPNI (premature detachment of the normally inserted placenta) was recorded in $12 \%(\mathrm{~N}=6)$, and in the control lot in $8 \%(\mathrm{~N}=4)$ of cases, without statistically significant difference (table no. 6).

Acute fetal distress at birth induced by oxytocin infusion was diagnosed in $24 \%(\mathrm{~N}=12)$ of cases, and in the control lot this indicator was $20 \%(\mathrm{~N}=10)$, with no significant difference between the two groups $(p=.504985)$.

Postpartum uterine bleeding was observed in patients born with oxytocin perfusion-induced birth in $54 \%(\mathrm{~N}=27)$ of cases, and in the control lot in $50 \%(\mathrm{~N}=25)(\mathrm{p}=.688921)$. In this case, too, there are no statistically significant differences. Regarding soft tissue ruptures, it was observed that in lot A the percentage is significant $76 \%(\mathrm{~N}=38)$, compared to the control lot where the percentage is $28 \%(\mathrm{~N}=14)$. Grade I and II cervical rupture was diagnosed 2 times more frequently in patients in the control lot than in lot A, namely in $16 \%(\mathrm{~N}=8)$ compared to $8 \%$ $(\mathrm{N}=4)$ of cases $(p=.218355)$.

Vaginal rupture was recorded in $28 \%(\mathrm{~N}=14)$ cases in lot $A$, compared to $4 \%(n=2)$ of cases in control lot $B$, with statistically significant differences between lots $(p=.001063)$. The result is significant at $\mathrm{p}<.05$.

Regarding the episiotomy, this was performed in $76 \%$ $(\mathrm{N}=38)$ of the cases in lot $\mathrm{A}$ and in $44 \%(\mathrm{~N}=22)$ of the cases in the control lot. The statistical difference is significant, $(p=$ .001091 . The result is significant at $p<.05$ but it can be explained by the increased share of primiparous in the baseline 


\section{CLINICAL ASPECTS}

lot (lot A) and multiparous in the control lot.

The Apgar score was used to assess the condition of the newborn immediately after birth, and the test was performed 1 minute and 5 minutes after birth. Thus, at birth $76 \%(\mathrm{~N}=38)$ of the newborns of the patients in the study lot had an Apgar 8 and over 8 , and only $24 \%(\mathrm{~N}=12)$ of the newborns of the patients in the control lot had an Apgar score of 7 and below 7 . The average value of the Apgar score at 1 minute in research lot A was estimated at 8.3 , and in control lot B higher, 8.6, with / without statistically confirmed difference (table no. 7).

Analyzing the perinatal results, we established that the average weight of children at birth in the baseline was 3445 grams, and in newborns in the control lot 3360 grams, the waist was $52.14 \mathrm{~cm}$ and $50.98 \mathrm{~cm}$ respectively, no difference statistics between the lots. The $p$ - value is .433202 . The result is not significant for $p<.05$. (table no. 8)

Induction of labor alters both labor and birth in significant directions. The cervix often needs to soften before synthetic oxytocin is effective: this substance causes contractions that become stronger faster than naturally occurring. The result is more difficult labor to manage. In addition, the uterine muscles never relax completely between contractions, increasing the stress imprinted on both the uterus and the baby, which explains the transformation of birth into cesarean section due to fetal hypoxia. Due to these potential risks to the uterus and the baby, continuous fetal monitoring is indicated.

Septic complications (endometritis) in the postpartum period occurred in the control lot in $10 \%(\mathrm{~N}=5)$ of cases, and in the baseline lot in $8 \%(\mathrm{~N}=4)$ of cases (Table no. IX). The state of hyperthermia was registered in $12 \%(\mathrm{~N}=6)$ of cases in lot $\mathrm{A}$ and in $8 \%(\mathrm{~N}=4)$ of cases in the control lot. Inflammatory complications of the postoperative wound more often developed in $8 \%(\mathrm{~N}=4)$ of the baseline lot, compared to $2 \%(\mathrm{~N}=1)$ in the control lot, without statistical significance. The $\mathrm{p}$ value is .504985 . The result is not significant for $p<.05$. The postpartum period in lot A was complicated by hemorrhage in $24 \%(\mathrm{~N}=12)$ of cases, and in the control lot in 30\% ( $\mathrm{N}=15),(p=.499207)$ Placental residues in the baseline lot (lot A) were assessed in $8 \%$ $(\mathrm{N}=4)$ of cases, and in the control lot in $16 \%(\mathrm{~N}=8)$ of cases, with statistically significant differences between lots. Lohiometry was observed with the same frequency in both lots.

The exacerbation of genital pathology in the postpartum period in the baseline lot was $10 \%(\mathrm{~N}=5)$ and $12 \%$ $(\mathrm{N}=6)$ in the control lot, with statistically significant differences, which demonstrates the positive impact of birth scheduling on reduction of genital pathology. The $p$-value is .003522 . The result is significant at $p<.05$

The study of cardiotocograms performed in labor in most cases did not show signs of fetal distress. The condition of the fetus at CTG was assessed as satisfactory in $82 \%(\mathrm{~N}=41)$ of cases in research lot $\mathrm{A}$, in $90 \%(\mathrm{~N}=45)$ of cases in control lot B. Suspicious CTG was assessed in $18 \%(\mathrm{~N}=9)$ of cases in research lot $\mathrm{A}, 14 \%(\mathrm{~N}=7)$ in control lot $\mathrm{B}$. The most common indicators of suspicious CTG were: lack of acceleration for over 40 minutes (reactive route); sporadic decelerations. By performing CTG during labor were detected: $5(10 \%)$ cases of pathological CTG in the lot of patients who used oxytocin, 2 (4\%) cases in the control lot. These above-mentioned cases were terminated by cesarean section urgently.

There are several situations when only cesarean section may be performed due to an infectious disease. $(30,31,32)$

The study of the action of the induction method on the evolution of the birth process showed that against the background of oxytocin administration, there is a decrease in the total duration of the birth process, compared to the control lot.
The first period of birth was shorter: in lot A constituting on average $372.80 \mathrm{~min}$, in the control lot this parameter was 429.70 min, which indicates a satisfactory time of opening of the cervix in the birth process. The duration of the expulsion period in the oxytocin lot $(19.90 \mathrm{~min})$ was significantly shorter than in the control lot $(25.50 \mathrm{~min})$. The duration of the third period of the birth process in the compared lots did not differ significantly: lot A (10.50 min) and the control lot (12.5 $\mathrm{min})$.

The research shows that there is a statistically significant correlation between the type of change in the CTG route and the time interval in which the birth took place. Thus, by administering oxytocin, each period of labor was shortened. As a result of this action, the period in which the pregnant woman was more vulnerable and the newborn could develop an infection due to GBS, was reduced. Regarding the neonatal results, no association was found between the Apgar score and the type of CTG change. This demonstrates that the intervention of the obstetrician in the recommended time for each situation leads to a favorable neonatal outcome.

\section{CONCLUSIONS}

The labor, the act of delivering an infant, may be natural (spontaneous) or artificial (induced). It starts with uterine contractions and continues with cervical change.

The election of one or another way for the vaginal delivery must be taken accordingly the benefits versus potential maternal and fetal risks associated with the procedure when comparing the two procedures by far the induced labor will keep the patient more into the hospital due to association of induced labor with $\mathrm{C}$-section and intrapartum interventions.

The most important finding of this study is probably the doubling of soft tissue ruptures among women with elective induction of labor.

This finding is worrying, as theoretically labor induction has not been medically indicated in many of these cases. Neonatal outcome is unaffected.

When compared with spontaneous labor, elective induction of labor at term does not appear to pose an increased risk to the mother or her fetus in a carefully selected patient population. However, elective induction of labor in a nulliparous patient with an unfavorable cervix, should not be discouraged.

Women facing a decision about induction should have the best available evidence to help them make an informed choice about the risks and benefits of the procedure. Clinicians should use the best available evidence to support decision making and need to acknowledge when insufficient evidence is available to definitively guide care.

A number of common indications for induction of labour do not have a strong evidence base from which to guide practice. Researchers and funding agencies should prioritise studies that can help to definitively guide care in these situations. In our experience elective induction of labour is a safe procedure for both the mother and fetus. Its use has been justified by the favourable perinatal outcomes compared to spontaneous onset deliver and with similar risk profiles.

The excellent safety however can only be achieved if a stringent adherence to the established indications and contraindications of elective induction is kept by the obstetricians.

Obstetricians, pediatricians and nurses involved in the hospitalization of pregnant women and in childbirth care, must be involved in women's health education for the implementation of prenatal programs for screening and treatment of GBS infection.

\section{Conflict of interest}

The authors declare no conflict of interest. All authors had equally contributed. 


\section{REFERENCES}

1. CDC. Heymann D.L. Handbook of communicable disease management; 2012.

2. Popa GL, Popa Course of medical microbiology - 2010 Accessed at: http://www.microbiologie.ro.

3. CDC 2017. Protect Your Baby from Group B Strep! Accessed at: https://www.cdc.gov/Features/GroupBStrep/

4. CDC 2017.Recommended regimens for intrapartum antibiotic prophylaxis for prevention of early-onset group B streptococcal (GBS). Accessed at: diseasehttps://www.cdc.gov/groupbstrep/guidelines/downlo ads/recommended-regimens.pdf.

5. https://www.cdc.gov/mmwr/pdf/rr/rr5910.pdf.

6. CDC. Prevention of perinatal group B streptococcal disease: a public health perspective. MMWR 1996;45(No. RR-7).

7. CDC. Prevention of perinatal group B streptococcal disease: revised guidelines from CDC. MMWR 2002;51(No. RR-11).

8. Eren A, Kucukercan M, Oguzoglu N, et al. The carriage of group B streptococci in Turkish pregnant women and its transmission rate in newborns and serotype distribution. Turk J Pediatr. 2005 Jan 1;47(1):28-33.

9. Kessous R, Weintraub AY, Sergienko R, Lazer T, Press F, Wiznitzer A, Sheiner E. Bacteruria with group-B streptococcus: is it a risk factor for adverse pregnancy outcomes? The Journal of Maternal-Fetal \& Neonatal Medicine. 2012 Oct 1;25(10):1983-6.

10. CDC, MMWR 2010. Prevention of Perinatal Group B Streptococcal Disease: Revised Guidelines from CDC, 2010 .

Accessed

https:/www.cdc.gov/mmwr/preview/mmwrhtml/rr5910a1. htm.

11. Alfirevic Z, Keeney E, Dowswell T, et al. Which method is best for the induction of labour? A systematic review, network meta-analysis and cost-effectiveness analysis. Health Technol Assess 2016; 20:1.

12. Alfirevic Z, Keeney E, Dowswell T, et al. Methods to induce labour: a systematic review, network meta- analysis and cost-effectiveness analysis. BJOG 2016;123:1462.

13. Manolescu LSC, Boeru C, Caruntu C, Dragomirescu CC, Goldis M, Jugulete G, Marin M, Popa GL, Preda M, Radu MC, Popa MI - A romanian experience of syphilis in pregnancy and childbirth - Midwifery - Volume 78, November; 2019. p. 58-63.

14. Leduc D, Biringer A, Lee L, Jessica Dy J, et al. Induction of labour. J Obstet Gynaecol Can. 2013;35(9).

15. https://patient.info/doctor/labour-active-management-andinduction.

16. https://sogr.ro/ghiduri-clinice- Induction of labour 2008, p 124.

17. Induction of labour (NICE clinical guideline 70). Royal College of Obstetricians and Gynaecologists; 2020.

18. Hadlock FP et al. Estimating fetal age: computer-assisted analysis of multiple fetal growth parameters. In: Radiology. 1984;152:497-501.

19. Hadlock FP. Sonographic estimation of fetal age and weight. In: Radiol Clin North Am; 1990. p. 28-39.

20. Hadlock F.P., Harrist R.B., Martinez-Poyer J. In utero analysis of fetal growth: a sonographic weight standard. In: Radiology. 1991;181(1):129-133.

21. Smith GC, Fretts RC, Stillbirth in: Lancet. 2007, no. 17 370(9600), p. 1715-25.

22. https://www.cdc.gov/mmwr/preview/mmwrhtml/rr5910a1. htm.

23. Committee on Obstetric Practice American Academy of Pediatrics- Committee on Fetus and Newborn - Apgar
Score October; 2015

24. Baranova A, Gowder SJ, Schlauch K, et al. Gene expression of leptin, resistin, and adiponectin in the white adipose tissue of obese patients with non-alcoholic fatty liver disease and insulin resistance. Obes Surg 2006;16:1118-25.

25. Stefanie N. Hinkle, Paul S. Albert, Pauline Mendola, Lindsey A. Sjaarda The association between parity and birthweight in a longitudinal consecutive pregnancy cohort. Paediatric and Perinatal Epidemiology. 2014;106-115.

26. Shah PS. Parity and low birth weight and preterm birth: a systematic review and metaanalyses. Acta Obstetricia et Gynecologica Scandinavica. 2010;89:862-875

27. Mayo Clinic Staff Fetal macrosomia. Available online at http://www.mayoclinic.org/diseasesconditions/fetalmacroso $\mathrm{mia} /$ basics/definition/CON20035423? $\mathrm{p}=1$ (accesat în 2 august 2018).

28. Gibson E, Nawab U. Large-for-Gestational-Age (LGA) Infant. Available online at http://www.merckmanuals.com/professional/pediatrics/peri natal-problems/large-for-gestationalage-lga-infant

29. https://sogr.ro/wpcontent/uploads/2019/06/5.Opera $\%$ C $8 \% 9 B i a-$ cezarian $\% \mathrm{C} 4 \% 83$.pdf.

30. Gorbulina O. A. Evaluation of the functional status of the utero-fetal-placental complex with various options for preinduction and labor induction / Novikova V. A., Fedorovich O. K., Lebedenko E. S. // Kuban Scientific Medical Medical No. 7 (112) 2009.- Krasnodar, - S. 114 118

31. Manolescu L, Marinescu P. Sex differences in HIV-1 viral load and absolute CD4 cell count in long term survivors HIV-1 infected patients from Giurgiu, Romania. Romanian Review of Laboratory Medicine. 2013;21(2):217-24.

32. Marinescu P, Manolescu LSC. Association of hepatitis B infection in patients with HIV Encephalopathy. Romanian Biotechnological Letters. 2012;17(6):7817-24.

33. Dragomirescu CC, Lixandru B.E, Coldea IL, Palade AM, Baltoiu M, Dinu S, Cristea VC, Manolescu L, Popa MI. Comparative analysis of different phenotypic and molecular methods used for the taxonomic identification of Corynebacterium spp. Isolated from clinical samples in Romania; Romanian Biotechnological Letters. 2017;22(5):12926-33. 